\title{
Social Distancing Challenges for Marginal Communities during COVID-19 Pandemic in Bangladesh
}

\author{
Nova Ahmed ${ }^{1,}$, Rahat Jahangir Rony ${ }^{1}$, and Kimia Tuz Zaman ${ }^{1}$ \\ ${ }^{1}$ Department of Electrical and Computer Engineering, North South University, Bangladesh \\ *Corrresponding author: nova.ahmed@northsouth.edu
}

Received: May 6, 2020; revised: May 14, 2020; accepted: May 19, 2020.

\begin{abstract}
This study presents the challenges of marginal communities in maintaining social distances during the COVID-19 pandemic. We focused on garment worker communities in Bangladesh. The current living conditions put the community at high risk due to the contagious nature of COVID-19. The study involved 55 garment workers (32 female) living in three different regions-Ashulia, Gazipur, and Mirpur of Bangladesh. Through a qualitative research method, three critical aspects were studied. First, the inability to maintain social distancing in the community living in close proximity. Second, there is a lack of concern about healthcare among the community and, finally, the absence of preparation for crisis management. The research work proposes policy level intervention for better healthcare in the light of the pandemic that can be helpful in the coming days.
\end{abstract}

Keywords: COVID-19, Garment workers in Bangladesh, Marginal community, Social Distancing, Healthcare

\section{Introduction}

Coronavirus disease, widely known as COVID-19, is an infectious disease, causing respiratory illness. The virus spreads primarily through droplets of saliva or discharge from the nose when an infected person coughs or sneezes. This is caused by a newly discovered coronavirus (WHO, 2020). Around 4.23 million people were tested positive, and more than 290K were killed around the world due to this virus attack as of May 2020 (WHO, 2020). COVID-19 pandemic has impacted the international community for its contagious nature (Khan et al., 2020; Hossain et al., 2020; Surveillances, 2020). Relevant authorities such as 
the World Health Organization (WHO) recommended social distancing as a preventive measure among communities. However, implementation of this strategy is difficult in congested regions, common in marginal communities (Saleh, 2020). This research work focuses on garment workers of Bangladesh during the COVID-19 emergence from the technology-based support perspective.

The garment industry is an important economic sector, earning significant revenues in Bangladesh. This sector was the second biggest apparel supplier in 2017 and earned around USD 29 Billion [Mirdha, 2018, BGMEA, 2019, World Bank, 2019]. Bangladesh earned more than $10 \%$ of its national GDP and received around $84 \%$ of the foreign earnings in the single fiscal year of 2018-2019 (The World Bank, 2020; BGMEA, 2020). Readymade garments (RMG) sector has created a huge amount of employment in Bangladesh. It is one of the leading economic sectors in Bangladesh (Islam et al., 2016). During 1983-84, there were 134 RMGs and 0.04 million workers. In 2012-13 the growth was so high that around 4 million workers worked in 5876 factories (Islam et al., 2016). Around 90\% workers are female (Islam et al., 2016) showing promises against patriarchal societal norms (Sabur, 2019; Sultana, 2010). The sector has been criticized for its lack of awareness to improve the quality of life for workers; particularly, when it failed to ensure safety during two back to back accidents. One involved a major fire incident in Tazrin Fashion, killing 112 workers (Bolle, 2014; Barua and Ansary, 2017), (Akhter, 2014; Sinkovics et al., 2016); the second one involved a collapse of a factory building named Rana Plaza killing around 1134 workers, injuring permanently 2500 workers (Islam et al., 2016; Sinkovics et al., 2016; Bolle, 2014). The accidents showed a lack of safety measures and negligence from the respective authorities. The incidents raised awareness requiring factories to ensure compliance based on internationally acceptable standards. There have been improvements in the working environment in compliant garments, while others (non-compliant ones) have not. However, there are ongoing concerns raised in contemporary studies whether the lives of garment workers have improved or not (Akhter et al., 2019; Steinisch et al., 2013; Akhter, 2014). On the other hand, the garments workers' health-related issues are often neglected in the factories, where workers experience poor health facilities (Akhter et al., 2019).

During the pandemic, developed countries have used advanced tracking systems for supporting communities, modeling the problem, and provide adequate solution approaches (Lee et al., 2020). There have been community efforts during the COVID-19 pandemic to support community using existing communication technologies such as toll-free numbers, social media-based awareness among others (Coronavirus BD, 2020), (Map, 2020), (Grameen Phone, 2020). However, communities, such as the garment workers' community, remained out of clear directives about the terminology of social distancing. The research presented here is a part of an initiative to explore ways to improve the garment workers' quality of life through desirable interventions. We present a qualitative study to understand garment workers' lives, along with follow-up discussion during the countrywide closure due to COVID-19 in Bangladesh. In the findings, we revealed:

- The challenges of social distancing in their living places

- Low concentration on personal healthcare, and

- The scenario of preparedness during the pandemic crisis.

The community living and working in close proximity is at high risk of community-spread of the contagious disease. In the first week of May 2020, many garments reopened to deal with a pandemic crisis, which also increases the risk at a higher level (Alam, 2020; Barua 
et al., 2020). Thus, this work presents the challenges which open up opportunities through policy intervention from the perspective of the authority and individual.

\section{Research Method}

The data were collected in two phases over three months. In the first phase, focus group discussions took place before the pandemic situation from January to March of 2020. The second phase took place during the pandemic emergence in the first week of April of 2020.

\subsection{Participant Recruitment}

Participants were recruited through local communicators (e.g., workers' house owners, house managers/caretakers) from urban and suburban regions near garments factories in Mirpur, Gazipur, and Ashulia in the greater Dhaka division. We went to participants' places on their weekends, where we could reach out to both male and female workers.

Phase 1: The first phase involved focused group discussion among $n=55$ participants' from a maximum of 40 different garments where male workers and female workers had separate groups. In each two-hour session, the discussion revolved around their lives, aspirations, and plans. The discussions were in Bangla. The groups are presented in Table 1. We had one-to-one discussions with five different people (Garment Factory Owners: 2, Field Coordinator: 1, and Factory Drivers: 2) who were closely associated with the community of the garment workers for many years. The participants' age ranged from the twenties to forty years; all participants were adults.

Table 1: Focus Group Participants.

\begin{tabular}{lrr}
\hline Group & Participant count & Gender \\
\hline Group 1 & 11 & $\mathrm{~F}$ \\
Group 2 & 7 & $\mathrm{M}$ \\
Group 3 & 12 & $\mathrm{~F}$ \\
Group 4 & 8 & $\mathrm{M}$ \\
Group 5 & 9 & $\mathrm{~F}$ \\
Group 6 & 8 & $\mathrm{M}$ \\
\hline
\end{tabular}

Phase 2: This phase involved individual discussion as a follow-up study during the lockdown of factories and all other amenities in early April through phone calls. We called several participants that we met in phase 1 , and $n=12$ participants ( 8 males and four females) have responded. Each discussion was around 10 minutes long, and the discussion involved queries about the community's preparedness. These communications were in Bangla.

\subsection{Study Analysis, Moderation, and Incentive}

The discussions were transcribed, translated, and openly coded for analysis individually by three different researchers. The inductive content analysis method was followed during analysis (Elo and Kyngäs, 2008; Braun and Clarke, 2006). In this paper, we only focus on findings regarding social distancing, health concerns, and community preparedness. The research was moderated by the researchers to ensure the voices are heard. All participants 
and local communicators are received BDT 300 along with food and gift items worth of BDT 500 .

\subsection{Research Ethics}

The study asked for written consent from participants where we explained the motivation of study to the participated workers. They had the freedom to leave the study at any time or may remain silent to specific questions if they were not comfortable. User data was anonymized. All our collected data are securely stored in a locked drive, and only researchers have access to it. The institutional review board approved the study.

\section{Findings}

The study incorporates three major findings that focus more on social distancing, healthcare, and crisis, presented as follows:

- Close Proximity of Residents;

- Lack of Concern regarding Healthcare, and

- No Adequate Preparation for Crisis.

We discuss these areas in the following subsections.

\subsection{Close Proximity of Residents}

The garment workers' residents had many shared spaces in their residences, such as kitchen, toilet, and corridors, where multiple families lived on the same floor collectively. Around six to eight families lived on a single floor. Due to sharing, women at each floor had to work at the same time in the kitchen areas where maintaining adequate distance was challenging. Workers' kids played in shared space, and male workers spent their free time together sitting somewhere close. The residents were located in congested locations where the entire community lives within quite a proximity. The community had a great understanding of their laborious daily routine. Figure 1(a) and Figure 1(b) shows a residential areas in suburban and urban locations respectively.

\subsection{Lack of Concern regarding Healthcare}

The garment workers community lived on their monthly or bi-weekly income without saving money for their healthcare. Some workers would compromise their primary care to ensure better turnaround time. They focused more on their aspirations, such as kids' education, building a new house in hometown, growing a poultry farm, rather than focusing on personal healthcare. On the other hand, they sometimes used to refrain from drinking water at the workplace due to workload. For example, a participant shared how she reduces her water intake to minimize her visit to the toilet and speedup her work. Simultaneously, few other female participants also raised their voices on this issue and agreed with that female worker.

"We work till evening at a stretch. By these times, we cannot go anywhere. We cannot even drink water and cannot go to the washroom. Management does not restrict us. Our workload 


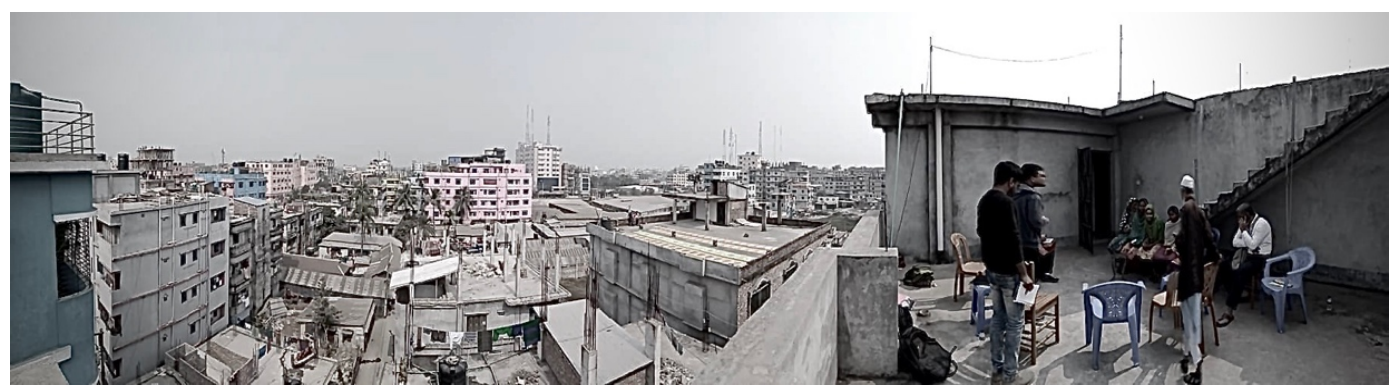

(a)

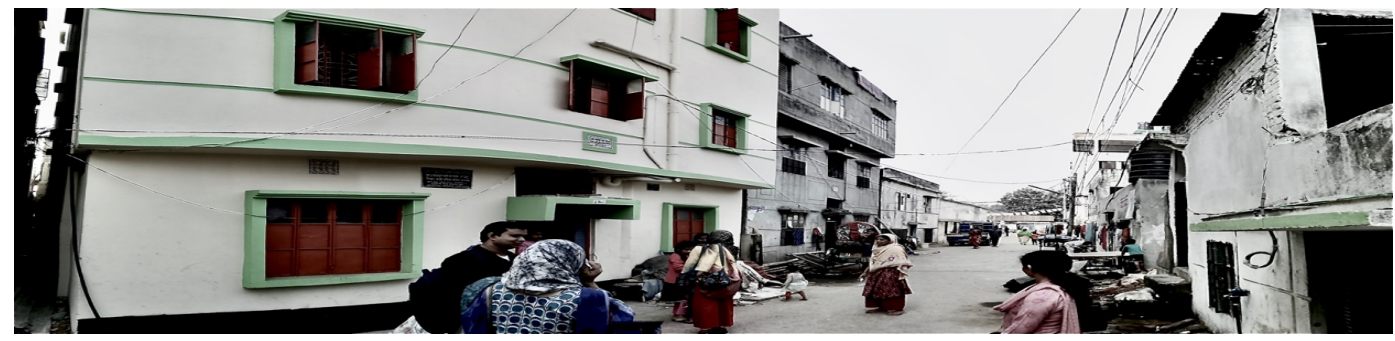

(b)

Figure 1: (a) A suburban resident (b) Urban resident of garment workers.

is so high that if we go to the washroom, it will take 5 minutes. If they (supervisors) do not find us anyhow, they shout at us. That is why we usually do not drink water that much to save time. We restrict ourselves in this case."- A female worker, Mirpur.

However, other female and male participants from the different areas did not mention such restrictions going to the restroom. At this point, a garment factory owner mentioned about increased productivity during Ramadan when participants are fasting, since restroom minimized restroom usage. It showed an inherent tendency to neglect the basic physiological requirements of the participants as well as owners-this relates to the existing body of literature on the healthcare of garment workers (Akhter et al., 2019).

"Workers work better during Ramadan. Workers do not need to drink water. There is no need to take food. On the other hand, workers somehow get obedient during Ramadan. So, this time actually, the productivity of the workers was high." - A factory owner, Dhaka (One to One conversation)

There was intense discussion around healthcare in all the focus group discussions showing it to have an emotional impact on workers. Many were worried about the potential risks of losing jobs in case of a significant health problem. There was a discussion around a sick person who did not participate in the focus group discussion but sat far away from the researchers. One worker mentioned how this man used to be a garment worker who was laid off when he had tuberculosis (TB). They did not give him any support to continue his treatment and livelihood. The person had a long working record of more than two decades in the factory. There was a direct discussion in Ashulia about scenarios around workers getting sick in the garments and how authority works in ways to hide this information from participants.

"We do not get any leave no matter what. Even if you die, we do not get leave. Once a girl had loose motion. She was so weak, and she asked for leave from the medical. They did not 
allow her to leave, gave her medicine, and asked her to take rest for 5 minutes; she even could not go home during lunch. She died there. When she died, they secretly took her to medical. They hid from us. They took the dead body to the hospital in a microbus and said that she died on the road-not in the garments. Then when people protested, they gave her family 2 lac. When there is any problem-they will put songs out loud. Suddenly they put loud music so that we cannot listen to the discussion or the chaos." - A female worker, Ashulia.

The congested workplaces created another level of concern around the ongoing COVID19 pandemic.

\subsection{No Adequate Preparation for the Crisis}

The garment sector had faced various accidents and ensured safety training and fire drills. Nevertheless, the workers were not prepared to take care of any possible health-related hazards at a personal level or authority level. Due to lockdown, all garments remained shut without providing monthly wages to the workers, which initiate unwanted financial instability in their daily life. The majority of the workers always face a lack of living standards where concerns around social distancing revealed in conversations. As we discussed earlier that workers are living in a congested place where they have the crisis of adequate living support such as shared washrooms and kitchen mostly. In a congested living condition as well as work conditions, maintaining social distance is challenging. Any contagious diseases (e.g., COVID-19) might harm a large scale in a shared space. There was a worker who articulated her concerns about social distancing clearly:

"We cannot maintain social distancing because our area is very congested. If you want to maintain it personally, I think you cannot maintain it. We have a shared kitchen. If anyone is infected here, the situation will be dangerous. I hope everything will be fine." - A female worker, Mirpur.

On the other hand, on a separate phone call, there was a worker who appeared content around the concept of social distancing who had pretty good living standard:

"We stay in separate rooms. We have a kitchen in our room. So we usually do not go to other rooms. We try to keep the distance. In the evening, we males sometimes discuss in front of our house. We use a mask. Other workers seem aware to me. They usually interact less at this time. Our kids do not go outside the building." - A male worker, Ashulia.

Workers never faced these situations before, and they do not know where and how to get emergency health support and how to deal with COVID-19. These workers wanted to return their workplace to deal with their crisis without thinking of their healthcare. This was a major concern among participants who were not sure about their next month's salary, about the closure of the factory and finally, about food security. Many were concerned about not receiving adequate support being in a group with a steady income.

"We are on an unpredictable journey. We just need food, nothing else. Only we need rice, red lentils, and oil, and that's it. We can eat at least." - A male worker, Mirpur

The COVID-19 crisis clearly showed the unpreparedness of the entire community. 


\section{Discussion}

The research work shows how a generic suggestion of social distancing is not applicable in the scenario of the population living in densely populated regions. The minimal distance among families and individuals living together asks for consideration where the entire community as a unit. Lack of concern about healthcare and returning to work might make the situation more complicated for them and the connected communities. A single person infected with highly contagious COVID-19 could impact the entire community very fast. Figure 2 shows different schematics for general social distancing and community social distancing, as suggested here.

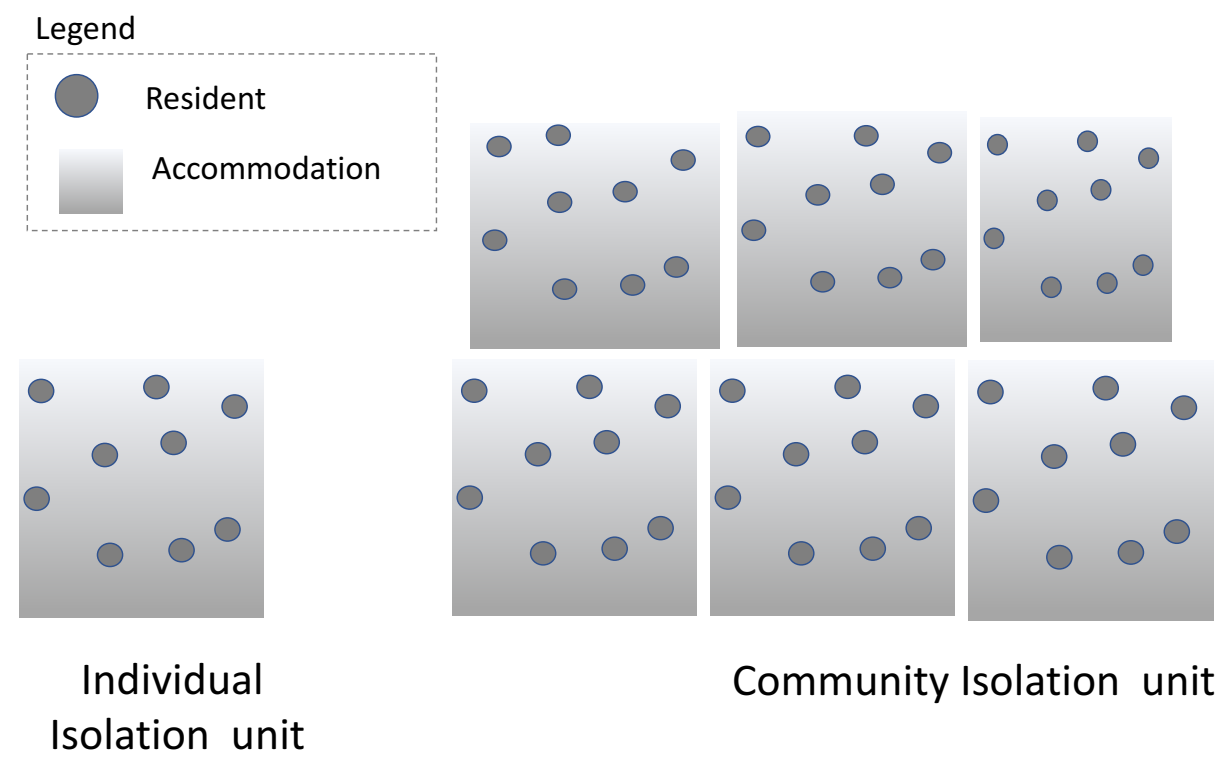

Figure 2: Generic social distancing (left) and community social distancing (right) concept.

The marginal communities in developing countries have unique living conditions that require special care in designing a support system. The work shows the lack of adequate preparedness of this group of their health, which exacerbates during the crisis. The current challenges open up opportunities to design better support and policy intervention in the coming days.

\section{Limitations and Future Work}

We could not reach out to 55 workers of phase 1, during the COVID-19 situations. We focused on many workers via phone calls, but only 12 workers received our calls. We still try to reach out to every single worker, and we hope that we will come up with more follow up studies in future submissions. 


\section{Conclusion}

We considered how garment workers in Bangladesh have responded to the social distancing guidelines during the COVID-19 pandemic. The general direction of maintaining social distance does not apply to communities living in congested areas such as the living conditions of garment workers. Garment workers living and working in congested areas are at high risk of COVID-19 infection. A single exposed person can become a super-spreader and infect the entire community living nearby. We suggest that attention must be given to the entire community and supported through adequate policy intervention.

\section{Acknowledgments}

We thank all the participants.

\section{Declarations}

Author Contribution: All the authors were an active part of the research project and writing, while the first author placed the entire work together.

Funding: From anonymous donor.

Conflict of interest: Not applicable.

Ethical approval: Through institutional review committee at North South University, IRB Number: 2020/OR-NSU/IRB-No.0501.

\section{References}

Akhter S (2014). "Endless misery of nimble fingers: The Rana Plaza disaster." Asian Journal of Women's Studies, 20(1), 137-147. doi:10.1080/12259276.2014.11666176.

Akhter S, Rutherford S, Chu C (2019). "Sufferings in silence: Violence against female workers in the ready-made garment industry in Bangladesh: A qualitative exploration." Women's Health, 15, 1745506519891302. doi:10.1177/1745506519891302.

Alam J (2020). Bangladesh reopens 600 apparel factories despite virus risk. Accessed April, 2020, URL https://abcnews.go.com/Business/wireStory/ bangladesh-reopens-600-apparel-factories-virus-risk-70379207.

Barua S, et al. (2020). "Understanding Coronanomics: The economic implications of the coronavirus (COVID-19) pandemic." SSRN Electronic Journal. doi:https://doi org/10/ggq92n.

Barua U, Ansary MA (2017). "Workplace safety in Bangladesh ready-made garment sector: 3 years after the Rana Plaza collapse." International Journal of Occupational Safety and Ergonomics, 23(4), 578-583. doi:10.1080/10803548.2016.1251150.

BGMEA (2020). "Bangladesh Garments Manufacturers and Exporters Association." Accessed April, 2020, URL http://www.bgmea.com.bd/home/pages/TradeInformation.

BRF Www.jBiomedAnalytics.org 
Bolle MJ (2014). "Bangladesh apparel factory collapse: Background in brief." Congressional Research Service, the Library of Congress.

Braun V, Clarke V (2006). "Using thematic analysis in psychology." Qualitative Research in Psychology, 3(2), 77-101. doi:10.1191/1478088706qp063oa.

Coronavirus BD (2020). “Coronavirus Bangladesh.” Accessed April, 2020, URL https:// corona.gov.bd/.

Elo S, Kyngäs H (2008). "The qualitative content analysis process." Journal of Advanced Nursing, 62(1), 107-115. doi:10.1111/j.1365-2648.2007.04569.x.

Grameen Phone (2020). Free health service TONIC launched for Grameenphone customers. Accessed April, 2020, URL https://www.grameenphone.com/about/media-center/ press-release/free-health-service-tonic-launched-grameenphone-customers.

Hossain MS, Ferdous S, Siddiqee MH (2020). "Mass Panic during COVID-19 Outbreak-A perspective from Bangladesh as a High-Risk Country." Journal of Biomedical Analytics, 3(2), 1-3. doi:10.30577/jba.v3i2.40.

Islam MS, Rakib MA, Adnan A (2016). "Ready-made garments sector of Bangladesh: Its contribution and challenges towards development." Journal of Asian Development Studies, 5(2). doi:10.17265/2328-7144/2019.01.004.

Khan S, Siddique R, Ali A, Xue M, Nabi G (2020). "Novel coronavirus, poor quarantine, and the risk of pandemic." Journal of Hospital Infection, 104(4), 449-450. doi:10.1016/j.jhin.2020.02.002.

Lee VJ, Chiew CJ, Khong WX (2020). "Interrupting transmission of COVID-19: lessons from containment efforts in Singapore." Journal of Travel Medicine. doi:10.1093/jtm/taaa039.

Map BUS (2020). "BRAC Urban Slum Map." Accessed April, 2020, URL http:// urbanslummap.brac.net/index.html.

Sabur S (2019). "Gender and Politics in South Asia." Oxford Bibliographies. doi:10.1093/OBO/9780199756223-0265.

Saleh A (2020). "COVID-19 threatens to cause a humanitarian crisis." Accessed April, 2020, URL https://bit.ly/2AMBMFv.

Sinkovics N, Hoque SF, Sinkovics RR (2016). "Rana Plaza collapse aftermath: are CSR compliance and auditing pressures effective?" Accounting, Auditing \& Accountability Journal, 29(4), 617-649. doi:10.1108/AAAJ-07-2015-2141.

Steinisch M, Yusuf R, Li J, Rahman O, Ashraf HM, Strümpell C, Fischer JE, Loerbroks A (2013). "Work stress: Its components and its association with self-reported health outcomes in a garment factory in Bangladesh-Findings from a cross-sectional study." Health \& Place, 24, 123-130. doi:10.1016/j.healthplace.2013.09.004.

Sultana A (2010). "Patriarchy and Women's Subordination: A Theoretical Analysis." Arts Faculty Journal, pp. 1-18. doi:10.3329/afj.v4i0.12929. 
Surveillances V (2020). "The epidemiological characteristics of an outbreak of 2019 novel coronavirus diseases (COVID-19)-China, 2020." China CDC Weekly, 2(8), 113-122.

The World Bank (2020). "The World Bank." Accessed April, 2020, URL https://databank. worldbank.org/source/world-development-indicators.

WHO (2020). "World Health Organization." Accessed April, 2020, URL https://www.who. int. 